\title{
Inspiriting a Disembodying of the "Dream of a Single Logic"
}

\author{
A Response to Elizabeth Mowat \& Brent Davis
}

\section{DALENE M. SWANSON}

University of British Columbia and University of Alberta (Canada)

In his book, Trying to Teach in a Season of Great Untruth, David Geoffrey Smith (2006) exhorts us to consider the violence embodied in the dream of the universality of a single logic. It is in the discursive acts of willing a single logic such as those found behind the motivations of various social and political activities exemplified in the newest globalizing iterations of empire that such a totalizing violence occurs. Such a colonizing gaze constructs a natural/naturalizing Truth in its own terms within which "the normal" is constituted as a stable, unified/unifying entity that tolerates no threat of "deviance". Set against this disturbing and warlike dream of singularity is the recognition of a pluralistic and complex world that (re)generates a vast network of associations, relationships, and interconnections that are far from simple, bounded or unified. More important, it is a world that is complicated and cannot be reduced to narrow singularities or neatly coherent and stable universals. It is this sense of a richly complex world that a complexivist approach endorses and legitimizes. It marks a shift in emphasis away from discrete objects of observation toward their fluid interconnections and the complex patterns of such relationships. This shift is not only a shift in what is being seen, but is a promise of the possibility of a shift in ways of seeing.

Regnant in the Rationalist enterprise of Enlightenment has been the vision of Mathematics as a grand universal that can describe the ultimate Truth about the world, the humanity within it, and the cosmos in its divinely scientific glory. How it unifies the 
truth of all knowing and all that can be known is what lies "out there" that is to be "discovered", a conquest articulated through Descartes' dream that everything in the universe be described according to Mathematics (Davis \& Hersh, 1986). This view of Mathematics aligns with a worldview that has shaped much of contemporary society and produced a modernist reality that is singular, unified, linearly progressive, categorizable, discrete, stable and fixed. In these terms, Mathematics, as a discrete body of knowledge, possesses a rigid structure to which new knowledge as it is "discovered" can be progressively added, but which as a whole is essentially coherent, fixed and promisingly unified/unifiable. The "reality" of the world that Mathematics presents to the world is, therefore, in its own image. This hubris and self-conceit has produced a self-enclosed "logic of immanence" (Hobson, 2004), which is the attitude that has defined Mathematics, and the attitude that results in its being treated with deference. In this ahistorical sense, it has committed a (symbolic) violence (Bourdieu \& Wacquant, 1992) on the world via the rationalist dream of the universality of a single logic, which has been imposed on the world in the names of Truth and Reality. This violence can most readily be seen in the historical development of Mathematics Education in many regions of the world that has, for the most part, followed the form of its master in presenting rigid curricula for students in which they have not been expected to actively participate, but to receive. In its conceit it determines who is permitted to eat from its royal table and who is not, as a function of their considered-innate "mathematical ability".

A loosening of this narrow vision of a rigid ahistorical conception of Mathematics can be achieved via a complexivist approach underwritten by network theory. Here, in their article, Interpreting Embodied Mathematics using Network Theory: Implications for Mathematics Education, to which I respond, Elizabeth Mowat and Brent Davis asseverate that mathematical knowledge possesses an underlying structure and topology that behaves as a complex system, with dynamic networks of interconnections and agents. In the same way, mathematics pedagogy can be understood in terms of similar complex phenomena at play, which mirrors in some way the development of mathematics over time, not as a rigid structure, but as a constantly contested field in which dynamic interactions and agents have shaped its course. In a network of nodes and links, certain ideas emerge in the kairos of various temporal and physical contexts, which grow, are reshaped or die within the ecology of the field.

It is a great relief to conceptualize mathematics and mathematics pedagogy in this way - as an inspirited escape from old conceptions of a rigidly structured body of knowledge as the grandest and "truest" of universals. The fact that the development of the discipline of mathematics and how it is taught are mutually constitutive is not difficult to realize, but that each is socially constructed within an ecology of meanings, interpretations, influences and contexts over historical time is duly recognized through a complexivist approach. This recognition is not available within the old classical, ideological paradigm. A complexivist approach also provides new insights for mathematics education research. Instead of the individual student and their individual cognition being the object of study, the focus lies in relationships; relationships to 
mathematics, to knowledge, to other students, to teachers, to a collective, to pedagogy, to all possible interactions, to events and phenomena inside and outside of classrooms, and to the environment and the embodied formations underlying meanings within it. The object of study is the complexity itself. Opening up insights to this broader, more intricate vision may provide teachers of mathematics with different ways of thinking about their students, about the nature of learning, of their influence in the process as an agent, of other agents of the dynamic system hitherto unrecognized, of emergent possibilities, and "perhaps (to help) them ... answer questions about complex educational systems that have (proven) intractable to date" (p. 4).

What a complexity approach does, perhaps better than any other, is to recognize that what may be seen in what we study is merely a hint of something possibly far greater, far bigger than ourselves, well beyond our frames of reference. This is a daunting idea but underscores the potentially fractal nature of our complex systems where one complex unit possesses self-similarity within it and may be a part of an ever greater complex whole. And in this strength of a complexivist approach lies its potential weakness in its take up in inquiry, for what we are seeing may not be a completeness in itself but a partial seeing of a fragment of a greater and even greater complexity, open even to others that influence it. As Elizabeth Mowat and Brent Davis note regarding Paul Cilliers' observations of characteristics of complex systems, "individual elements are ignorant of the behaviour of the whole system in which they are embedded.... (Cilliers, 1998, p.119-123)" (p. 4 ). To assert that teachers or researchers as elements of the complex pedagogic system of the classroom may "see" the complex system within which they are implicated from outside of the system and outside of themselves interacting within that system can only ever be paradoxical and partial at best if not impossible. It is even less plausible within the terms of emergence to act upon that "seeing" as a somewhat rational consequence or controlled response to it. Perhaps in some resonance with The Double Slit Experiment and Heisenberg's Uncertainty Principle derived from it (see http://www.youtube.com/watch?v=a qRKjeam5w or

http://www.youtube.com/watch?v=HUya5UoeKWs), we are reminded that the very process of observation may change the nature of the interactions and hence the system itself well beyond what can be seen and observed within this open complex system. Our frames of reference may not capture enough of the "pattern", the influences of/on that pattern. The boundedness of classroom walls is a somewhat arbitrary reference of "borderliness" to mark the ends of our frames of observation.

One of the dangers of the language of complexity science as is often applied is its naturalizing discourse. In providing a language of description of complexity within so many fields of endeavour, (thereby claiming transdisciplinarity), and of providing a new vision of how the world operates, it falls into the same paradigm, even as it contests it, of creating a unifying truth of the world, of a new meta-discourse, of participating in the dream of the universality of a single logic, even if contradictorily. Taking the discipline of Sociology for one, for which complexity is said to have influence, is to subsume it within the guiding principles of complexity science, reducing its activities to the terms of complexity science. Here "conflict" is merely evidence of a complex system operating far 
from equilibrium, but which cannot speak to the ethics of the conflict, of human desire for justice or peace, in and of itself other than that this would be a "natural condition" of such a system outside of a state of equilibrium. In a post-modern and post-colonial condition, where reflexivity and critical interrogation of the social, cultural, ethical and even spiritual elements of the conflict would be valued, very little of these important aspects of the human condition can be articulated in the language of complexity science in ways that are very much more than trivial or obvious. Just as Mathematics, which represented divine and absolute Truth has been dethroned by recognizing the paradoxes, ambiguities and contradictions inherent in its development and constitutive of its historical knowledge-base, so too should these complexities, contingencies and ambivalences be present in our language of description and methods of inquiry of complex phenomena through a complexity science lens.

Finally, recognizing that complex systems are diverse and that it is this diversity that sustains them ecologically, we should desist from the old paradigm of engagement that lures us to the passivity of singularity in ways that build on assumptions as uncontested truths, as forms of accepted knowing. Statements taken as accepted such as "the structure of mathematics is..." (emphasis inserted, p. 3), (when some non-Western cultures might not have used such a term as mathematics for the activities they participated in, let alone viewed them as having a separate structure), or making claims to coherent characteristics of (for example) mathematics' condition, while seemingly obvious, still claim a truth about the natural, doxic order of things. It is a subtle point, but I believe important nonetheless. Embracing the idea of a complexity larger than ourselves has its responsibilities. One might be to inspirit a disembodying of the dream of a single logic. We might also be reminded of Socrates' point that all that we really can know is that we do not know, and that all that we might "see" of unities of a complex world are shadows of images of realities dancing by the light of flickering flames ... perhaps dancing shadows on the walls of Plato's cave.

\section{References}

Bourdieu, P. \& Wacquant, J.D. (1992). An invitation to reflexive sociology. Chicago: The University of Chicago Press.

Davis, P.J. \& Hersh, R. (1986). Descartes' dream: the world according to mathematics. Boston: Houghton Mifflin Company.

Hobson, J. (2004). The Eastern origins of Western civilization. Cambridge, UK: Cambridge University Press.

Smith, D. G. (2006). Trying to teach in a season of great untruth: globalization, empire and the crises of pedagogy. Rotterdam: Sense Publishers.

About the Author

Dalene M. Swanson holds Adjunct Professorships at The Universities of British Columbia and Alberta, Canada. Most recently, she completed a two-year Social Sciences and Humanities Research Council of Canada postdoctoral scholarship. Dalene's research 
interests span curriculum studies, mathematics education, narrative and arts-based methodologies, critical theory and cultural studies. Focusing on socio-political contexts of education, she has commitments to democracy, interdisciplinarity, indigeneity, and social, ecological and global justice. Dalene was born in South Africa and holds degrees in mathematics and education from the University of Cape Town, and a Ph.D. in Curriculum Studies and Mathematics Education from The University of British Columbia. Her narrative-based dissertation looked at the construction of "disadvantage" in social context in historically and culturally diverse schools in South Africa. This research addressed critical issues in mathematics education and contested hegemonic practices in schooling and society. This work was recognized with four Canadian and international awards in Qualitative Research and Curriculum Studies.

(C) Copyright 2010. The author, DALENE M. SWANSON, assigns to the University of Alberta and other educational and non-profit institutions a non-exclusive license to use this document for personal use and in courses of instruction provided that the article is used in full and this copyright statement is reproduced. The author also grants a non-exclusive license to the University of Alberta to publish this document in full on the World Wide Web, and for the document to be published on mirrors on the World Wide Web. Any other usage is prohibited without the express permission of the authors. 